\title{
COMPARAÇÃO ENTRE OS MODELOS DE CMIP5 E A CLIMATOLOGIA DA PRECIPITAÇÃO SEMANAL SOBRE O BRASIL TROPICAL
}

\author{
Naurinete de Jesus da Costa Barreto ${ }^{1 *}$; David Mendes ${ }^{1}$; Paulo Sergio Lucio ${ }^{1}$ \\ ${ }^{1}$ Universidade Federal do Rio Grande do Norte; Natal - RN, Brasil \\ *netebarreto@gmail.com
}

\section{RESUMO}

Este estudo apresenta uma visão geral do desempenho dos modelos climáticos globais que participam do Projeto de Intercomparação de Modelos Acoplados Fase 5 (CMIP5) na simulação da variabilidade semanal da precipitação pluvial sobre o Brasil Tropical (BrT). As médias semanais calculadas para regiões específicas de chuva do BrT foram comparadas com as simuladas por oito modelos do CMIP5. As análises mostram que os modelos geralmente são capazes de simular o sinal do padrão semanal médio tanto do ponto de vista espacial e como temporal, porém alguns apresentam pouca sensibilidade à magnitude.

\section{INTRODUÇÃO}

A variabilidade climática global e as mudanças causadas por processos naturais e fatores antrópicos podem resultar em grandes problemas ambientais que afetam o mundo durante o século 21. Essas alterações têm o potencial de alterar os valores sazonais de precipitação na América do Sul e os padrões de variabilidade natural. A maioria dos modelos é capaz de reproduzir as características básicas do ciclo sazonal precipitação, como o noroeste e sudeste migração de precipitação sobre a América do Sul tropical e a máxima precipitação observada nos Andes (Grimm, 2011).

\section{MATERIAL E MÉTODOS}

Os dados de precipitação diária gradeada abrangendo o período de janeiro de 1979 a dezembro de 2004, obtidos a partir da base de dados do "Climate Prediction Center unified gauge" (CHEN et al., 2008) e dados de simulação climática de oito modelos incluídos no projeto CMIP5 ( A Figura 1 apresenta as regiões que foram selecionadas para calculo das médias semanais de precipitação com o objetivo de compara os valores simulados pelos modelos do CMIP5 e os dados observados. 
), considerando o experimento "Historical" (TAYLOR et al, 2012). A Figura 1 apresenta as regiões que foram selecionadas para calculo das médias semanais de precipitação com o objetivo de compara os valores simulados pelos modelos do CMIP5 e os dados observados.

. Tabela 1: Modelos utilizados neste trabalho

\begin{tabular}{c}
\hline NOME DO MODELO \\
\hline (GFDL-ESM2M) - (NorESM1-M) - (CNRM-CM5 $)-$ \\
$($ HadGEM2-ES $)-($ INMCM4) $-($ MIROC-ESM $)-$ \\
$($ INMCM4 $)-($ CanESM2M $)$
\end{tabular}

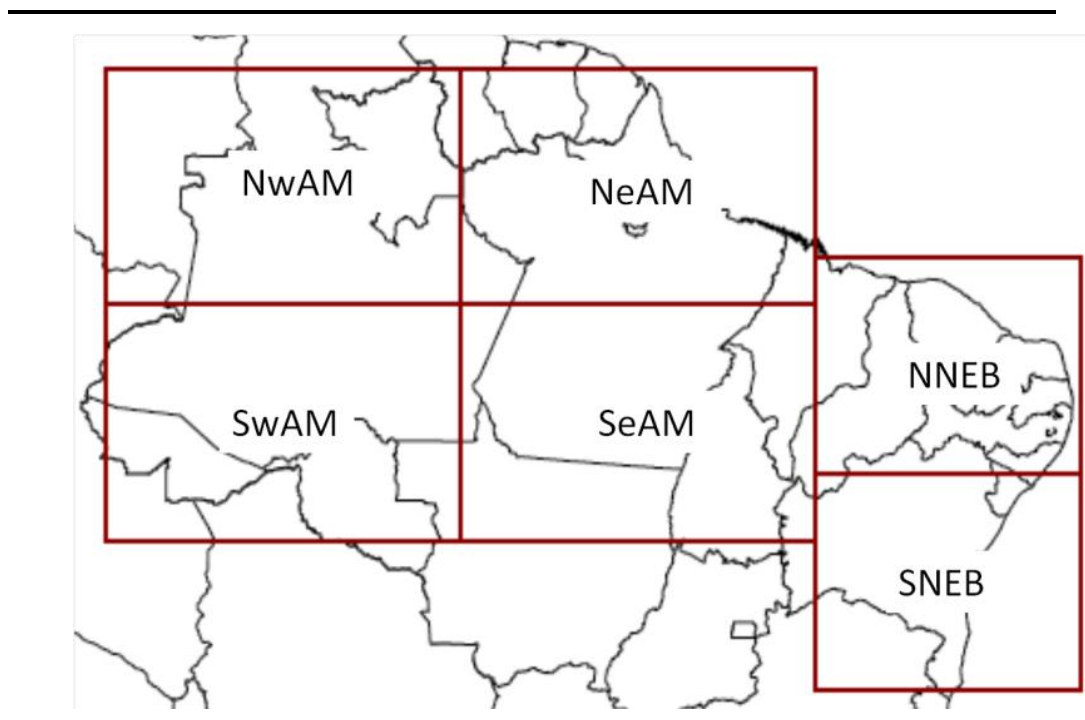

Figura 1: Os retângulos vermelhos indicam o Noroeste (NwAM), Nordeste (NeAM), Sudeste (SeAM) e Sudoeste (SwAM) da Amazônia, e o Norte (NNEB) e Sul (SNEB) do Nordeste do Brasli.

Fonte: (Barreto et al., 2013).

\section{RESULTADOS E DISCUSSÕES}

A Figura 2 apresenta a variação precipitação semanal para as regiões selecionadas na Figura 1, cada região apresenta estação chuvosa e seca com períodos e intensidades diferentes. O BrT tem sua estação chuvosa concentrada entre o verão e o outono austral. $\mathrm{O}$ Nordeste exibe máximos concentrados em poucos meses do ano e período de estiagem prolongado. O NwAM apresenta chuva intensas ao longo do ano e sazonalidade diferenciada 
devido a proximidade com linha equatorial. Avaliando variação sazonal, tem-se sazonalidade mais intensas no NeAM e SwAM do que no NwAM e SeAM, estas últimas apresentam precipitação média acima de $4 \mathrm{~mm} \cdot \mathrm{dia}^{-1}$ ao longo do ano. As duas regiões do NEB apresentam regime chuvoso muito concentrado em poucos meses e período de estiagem bem longo, apesar de ser mais bem observado esse padrão no NNEB, em geral o período chuvoso se configura de meados de dezembro até final de maio.

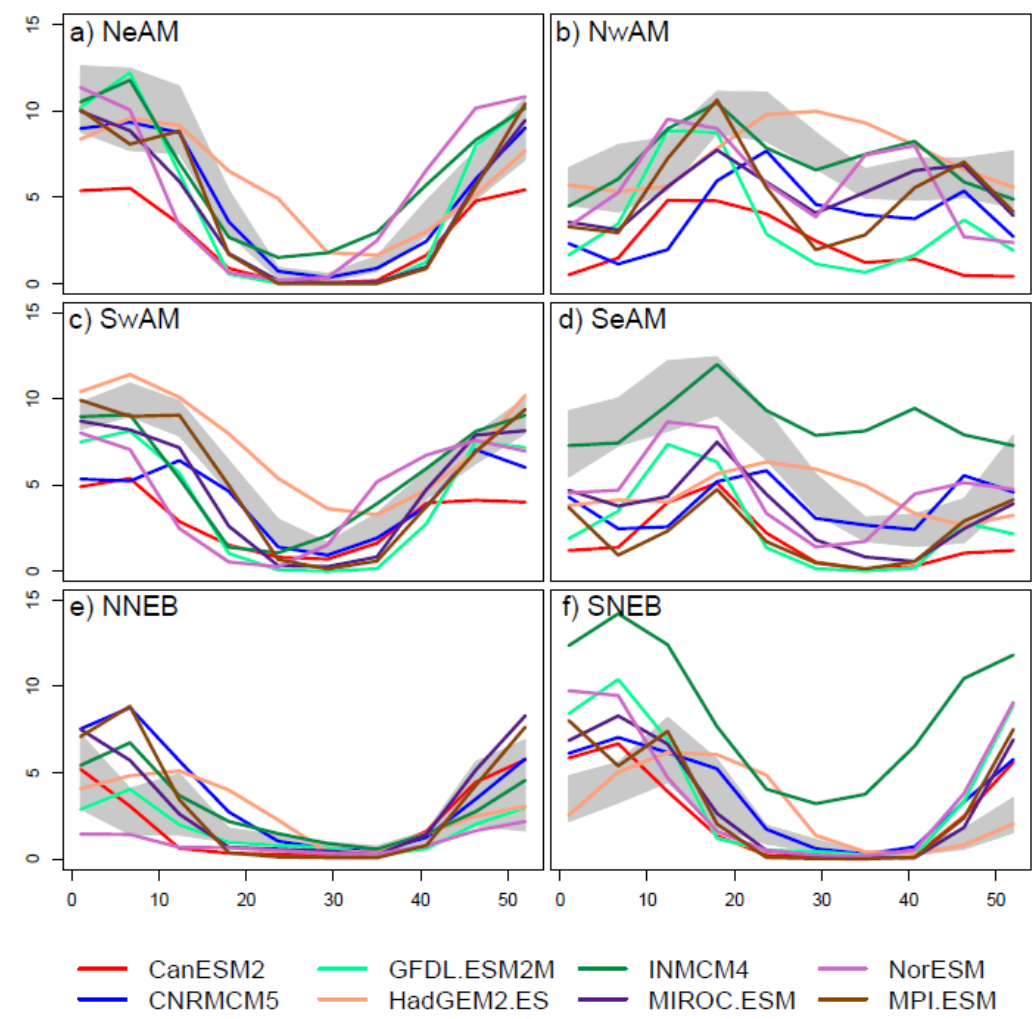

Figura 2: Variação Semanal de Precipitação $\left(\mathrm{mm} \mathrm{dia}^{-1}\right)$, nas regiões selecionadas, valores sombreados representam o intervalo entre o 1 quartil e 3 quartil dos dados observados.

\section{CONCLUSÃO}

Entre os modelos de simulação climática, nota-se que apesar de apresentarem algumas diferenças quando comparados ao observado, no geral eles apresentam boa sensibilidade à variação sazonal, em boa parte das regiões, em especial sobre o NNEB e SwAM. O INMCM4 foi o modelo que apresentou valores superestimados no SNEB e SeAM, nas outras regiões apresentou boa sensibilidade 


\section{AGRADECIMENTOS}

A coordenação de aperfeiçoamento Pessoal de Nível Superior (CAPES) pelas bolsas de doutorado da autora (Naurinete Barreto).

\section{REFERÊNCIAS BIBLIOGRÁFICAS}

BARRETO, N. J. C.; MENDES, D.; LUCIO, P. S. Avaliação Preliminar da Sensibilidade dos Modelos Do CMIP5 a Precipitação Sazonal do Brasil Tropical. Revista Brasileira de Geografia Física, 2013.

CHEN, M. et al. Assessing objective techniques for gauge-based analyses of global daily precipitation. Journal of Geophysical Research, v. 113, n. D4, p. D04110, 2008.

GRIMM, A. M. Interannual climate variability in South America: impacts on seasonal precipitation, extreme events, and possible effects of climate change. Stochastic Environmental Research and Risk Assessment, v. 25, n. 4, p. 537-554, 2011.

TAYLOR, K. E.; STOUFFER, R. J.; MEEHL, G. A. An overview of CMIP5 and the experiment design. Bulletin of the American Meteorological Society, v. 93, n. 4, p. 485, 2012. 